\title{
INTRINSIC REVIEW AND MISE-EN-SCÈNE STUDY OF GOOD WILL HUNTING MOVIE
}

\author{
Sri Purwati \\ SMP Negeri 1 Tanggungharjo, Grobogan \\ Email: ipunkwatinugroho41@gmail.com
}

\begin{abstract}
Watching movie is interesting and important. It can give people pleasure and fresh. People can also learn so many things about life from movie. Film or movie has an initial story, idea, or commission, through screenwriting, casting, shooting, sound recording and pre-production, editing, and screening the finished product that is called as mise-en-scène. Mise-en-scène plays an important role to convey many things in a film or movie such as conveys message or moral value, build a narrative, etc. Based on those facts, this research tries to analyze the elements of mise-en-scène in Good Will Hunting movie, how miseen-scène can work to communicate mood and meaning in Good Will Hunting Movie.

The method of the research are method of observing data, method of collecting data, method of analyzing data, and presenting data. In the method of collecting data by doing observation data, document data, and audiovisual data that the primary data used the movie of Good Will Hunting. Analyze data based on its structural elements from movie, individual's observation by observing movie and conducted the data analysis to describe mise-en-scène of the movie.

The result of the research shows that applying of camera technique used in this movie is so many varieties. Long shot contains landscape but gives the viewers more specific idea of setting. A long shot may show the viewers the building where the action will be taken. Full shot contains a complete view of the characters. From this shot, viewers can take in the costumes of characters and may also help to demonstrate the relationships between characters. Close-up contains just one character's face. This enables viewers to understand the actor's emotions and also allows them to feel empathy for the character. Overall the composition and cinematography techniques used in this movie are good.
\end{abstract}

Keywords: Movie, Good Will Hunting, Mise-en-scene, Cinematography

\section{Introduction}

Movie is one branch of the art that usually contains someone's life story, fiction, and biography as an entertainment for people. Movie usually describes about love, life, politic, violence, etc. According to Bourdieu as quoted by Kathie Njanie (2007, p.2), symbolic violence is violence wielded with tacit complicity between its victims and its agents, insofar as both remain unconscious of submitting to or welding it.

Movies, also known as films, are types of visual communication which uses moving pictures and sound to tell stories or teach people something. People in every part of the world watch movies as a type of entertainment, a way to have fun. For some people, fun movies can mean movies that make them laugh, while for others it can mean movies that make them cry, or feel afraid. Sumarno (1996, p.13) sates that films or movies play role as a mean of 
communication used to provide entertainment that presents stories, events, music, drama, humor and other technical offered for public.

Making film or movies is not an easy work. Hence, there are so many people whom they call them the movie lovers watching movies to appreciate the hard efforts of filmmaker in presenting and realizing his ideas in film or movie. The viewers certainly play a role in the continuity of film production. Film or movie is not just a matter of story, but also contains complex information about many things. For example, by watching film, people can understand the culture of a place or a country to the way of thinking of certain groups or people in one country.

Film or movie can also be a source of learning for making films or movies. Many filmmakers watch films or movies to learn about market demand, scene settings, plot development, or just looking for inspiration in making films. But before people make a film or movie they should know how a film or movie is made. Filmmaking is the process of making a film or movie, generally in the sense of films intended for extensive theatrical exhibition.

Filmmaking involves a number of discrete stages including an initial story, idea, or commission, through screenwriting, casting, shooting, sound recording and pre-production, editing, and screening the finished product before viewers see that may result in a film release and exhibition. They are all that in filmmaking called as mise-en-scène. Due to those conditions, the researcher believes that it is needed to learn mise-en-scène if people want to make a film or a movie and how the elements work together to communicate mood and meaning.

\section{Theoretical Framework}

\subsection{What a Film or Movie is}

Film or movie is one of entertainment which cannot be separated from people's life now. It also becomes a medium to describe about human life and all aspect of problems, and it can retell a story or event in the last time. According to Hornby (1995; p.434) in Oxford Advanced learner's Dictionary of Current English: "Film is a story etc recorded as set of moving pictures to be shown on television or at cinema”.

\subsection{How A Film or Movie is Made}

Filmmaking or in an academic context, film production is the process of making a film, generally in the sense of films intended for extensive theatrical exhibition. Filmmaking involves a number of discrete stages including an initial story, idea, or commission, through 
screenwriting, casting, shooting, sound recording and pre-production, editing, and screening the finished product before viewers see that may result in a film release and exhibition.

Film production consists of five major stages:

\section{a. Development}

Development is the first stage in which the ideas for the film are created, rights to books/plays are bought etc., and the screenplay is written.

\section{b. Pre-production}

It is the part of arrangements and preparations are made for the shoot, such as hiring cast and film crew, selecting locations and constructing sets.

\section{c. Production}

The raw footage and other elements for the film are recorded during the film shoot.

\section{d. Post-production}

The images, sound, and visual effects of the recorded film are edited and combined into a finished product.

\section{e. Distribution}

The completed film is distributed, marketed, and screened in cinemas and/or released to home video.

\subsection{Mise-en-scène}

Mise-en-scène, pronounced meez-ahn-sen, in film or movie is a term used to describe the setting of a scene in a movie or a film. It refers to everything placed on the stage or in front of the camera; including people. Mise-en-scène is derived from French "placing on stage". The French term mise-en scène is used to mean staging or putting on an action or scene. Whatever comes in front of the camera falls under the umbrella term mise-en-scène. It is also commonly used to refer to single scenes within the film to represent the film.

Bordwell and Thompson (2003, p.66) says that in cinematic terms, mise-en-scéne can be referred to all the elements of a film that we see in front of the camera and the way it is arranged. While Barsam and Monahan (2009, p.74) state that the elements, which include décor, lighting, space, costumes and acting, have an important role in imparting a mood to the story and delivering a meaning to the visuals, thus playing a crucial role in signifying the director's narrative mastery. It involves visual composition, the movement and position of on-screen actors and the properties set as part of stage design. 
From the above description, we can see that the arrangement of everything that appears in the framing; actors, lighting, décor, props, costume, is called mise-en-scène. The frame and camerawork are also considered part of the mise-en-scène of a movie. Good understanding and analysis of mise-en-scène will result in effective creative practical outcomes. Actor's performances contribute a great deal to a film's meaning. Most narrative feature films tell stories about human being and the conflicts they face.

\section{a. Casting}

Casting is part of the pre-production process. Casting is the process of selecting and hiring actors to play the roles and characters in a film production. Casting is done by the film director and casting department of film production.

\section{b. Acting Style}

Acting is a combination of body movements and voices of human or non-human characters. McDonald (2000, p.28) states that nevertheless acting, in supports from other components, crucially expresses the meaning of the film. For a viewers, the activity of reading a performance involves the bringing together of actor and character, and the interpretation and evaluation of acting has tended to assess whether or not the actor has 'become' the character.

\section{c. Performance}

Performance includes physical expressions, vocal delivery and interaction between performers; with reference to issue of staging or choreography where relevant. Like setting and costume, figure expression and movement are important elements of mise-en-scéne used by the director to support the narrative as well as help develop the thematic unity of a film. Figure expression refers to the facial expressions and the posture of an actor, whereas figure movement refers to all other actions of the actor, including gestures.

\section{d. Figure Placement (Blocking)}

The meaningful arrangement of the actors on the set is called blocking. Blocking is an area overlooked by actors; the positioning and movement of the characters to tell the story in visual terms. This placement can suggest the attitudes of the characters toward one another, so the story situation is conveyed to the viewers with or without dialogue. It makes the viewers understand, at times contrary to the dialogue, the inner meaning existing within and between characters. 


\section{e. Costumes}

Costumes or clothing and its accessories, are the only aspect of mise-en- scéne that is easily noticeable by almost everybody. It includes makeup, hair, and clothes or wardrobe choices that are used to show the personality of the character.

\section{f. Make-up}

A make-up applies cosmetics from the top of a person's head to the top of their breastbone. Like other components of mise-en-scène, make-up is also genre specific. Make-up has a wide range of importance in the composition of a character. Make-up can reflect the attitude and behavioural traits of a character. It all depends on the complexity of the special effects make-up and how important the lead special effects make-up is.

\section{g. Props}

Props which is short for properties are items used or carried by an actor, or items on the set. Props can tell the viewers where the drama is set (place). The time period of the drama. They can also give information about a characters: age, personality, mood, occupation. Props is the term given to an item carried or worn by a character e.g. glasses, handbag, wallet, etc. Props is the term given to an item placed on the set, usually part of it e.g. a lamp, clock, picture, etc.

\subsection{How Mise-en-Scéne Works in A Film or Movie}

The aspect of mise-en-scéne plays an extremely active role in film and periodically may assume as much importance in the total film as the action, or events. Through mise-en-scène, character and narrative development, themes, ideologies and aesthetics are conveyed to viewers through careful composition of the visual elements recorded by the camera. Mise-en-scène is central to analysis work and pulls in understanding of narrative, values and themes. It aligns spectators' interpretations and responses. Good understanding and analysis of mise-en-scène will result in effective creative practical outcomes.

Jayakrishnan and Amrita Vishwa (2015) emphasized that in cinematic terms, mise-en-scene can be referred to as all the elements of a film that we see in front of the camera and the way it is arranged (Bordewell and Thompson, 2003). Those elements, which include décor, lighting, space, costumes and acting, have an important role in imparting a mood to the story and delivering a meaning to the visuals, thus playing a crucial role in signifying the director's narrative mastery. It involves visual composition, the movement and position of on-screen actors and the properties set as part of stage design (Barsam and Monahan, 2010). 
Jurnal CULTURE (Culture, Language, and Literature Review), 8 (2), November 2021, 170-185

Copyright (C) 2021, Jurnal CULTURE (Culture, Language, and Literature Review), e-ISSN 2775-4618, p-ISSN $2355-8660$

\section{Research Methods}

\subsection{Research Design}

In this research, the researcher used qualitative textual analysis method. The data which were taken are texts or words. The methodology section allows the reader to critically evaluate a study's overall validity and reliability. Vanderstoep and Johnston (2009, p.7-8) states that qualitative research is a research that produces narrative or textual descriptions of the phenomenon under study, so the researcher provides richer and more in depth understanding of the population.

\subsection{Method of Data Collection}

The data collection method used in this study were by observation, documentation, and audiovisual. The primary data that the researcher used in this study was the movie of Good Will Hunting, the secondary data were obtained from some sources, such as books, articles, and journals related to mise-en-scène. In collecting data, watch-read-write technique was used.

\subsection{Method of Data Analysis}

In analyzing data, the researcher applies a descriptive approach. The steps taken by the researcher in analyzing the data are the first is analyzing the data based on its structural elements. Focus will be paid on the structural analysis of the movie. The second step is analyzing the data based on individual's observation that is by observing movie. The data analysis was conducted to describe mise-en-scène of the movie. It can be trusted that it was used to achieve dependability, conformability, transferability, and credibility.

\section{DISCUSSION}

\subsection{Intrinsic Review of Good Will Hunting}

Good Will Hunting is a 1997 drama film directed by Gus Van Sant and written by Matt Damon and Ben Affleck. The film took a set in Boston, Massachusetts. The film tells the story of Will Hunting (Matt Damon), a troubled Irish-Catholic young man who is gifted with extraordinary mathematical skills, as well as being a miracle and self-taught, but his job is a menial worker as a janitor at the Massachusetts Institute of Technology. Prone to violence and extremely loyal to his friends, Chuckie (Ben Affleck), Morgan (Casey Affleck) and Billy (Cole Hauser), Will has pushed away everyone else whom has tried to get close to him because of his abusive past and introverted personality. 
Will : What do I want a way outta here for? I want to live here for the rest of my life. I want to be your next door neighbor. I want to take our kids to little league together up Foley Field.

After solving a complex mathematical equation at the Massachusetts Institute of Technology, Will is discovered by Professor Gerald Lambeau (Stellan Skarsgard), a Fields Medal-winning mathematician who sees a lot of potential in Will Hunting, and he sends him to psychiatrist named Sean Maguire (Robin Williams). At the same time, while Will has a counselling with the psychiatrist, Will Hunting is having a close relationship with the beautiful girl, Skylar (Minnie Driver), who is also confronting her own personal problems. Will has to learn to overcome his deep fear of abandonment with Sean's help in order to learn how to trust and love the people who care about him. Good Will Hunting movie has a brilliant screenplay in everything, dialogue, character, structures, story, and in service how the viewers experience emotions.

Sean : My wife's been dead two years, Will. And when I think about her, those are the things I think about most. Little idiosyncrasies that only I knew about. Those made her my wife, we get to choose who we're going to let into our own weird little worlds. You're not perfect. And let me save you the suspense, this girl you met isn't either. The question is, whether or not you're perfect for each other. You can know everything in the world, but the only way you're findin' that one out is by giving it a shot.

\subsection{Mise-en-Scéne in Good Will Hunting Movie}

Good Will Hunting is a film which conveys many related themes and messages to its viewers. The film took place between April and June 1997. Although the story is set in Boston, and many of the scenes were done on location in the Greater Boston area, many of the interior shots were filmed at locations in Toronto, with the University of Toronto standing in for Massachusetts Institute of Technology and Harvard University. The classroom scenes were filmed at McLennan Physical Laboratories of the University of Toronto and Central Technical School. Harvard normally disallows filming on its property, but permitted limited filming by the project after intervention by Harvard alumnus John Lithgow. Likewise, only the exterior shots of Bunker Hill Community College were filmed in Boston, however, Sean's office was built in Toronto as an exact replica of one at the college. 


\subsubsection{The Opening (Beginning) Scene}

It takes a rundown house that is the main character lives. The main character, Will Hunting, the Static or flat character, Chuckie Sullivan, Will's closest friend, and the stock character that is a woman, Will's neighbor who is sitting in front of her house, is introduced. We say that the woman is as the stock character, because she just appears once in the whole movie, just in the opening scene. This scene was accompanied by music of orchestral "Between the Bars" arranged by Elliott Smith. In Massachusetts Institute of Technology, another characters are intoduced. They are Gerald Lambeau, the Math Professor of Massachusetts Institute of Technology, Tom, Lambeau's assistant, and the others are so many students in Lambeau's class.

The costumes or clothing they wear and the accessories are for daily clothes, and so does the use of make up. For examples the clothing worn by Chuckie, a white track suit which implies that he is young and sporty. There is no special for the view. The props used are also for the daily life, the home of Will, fulfill with the home furniture, like chairs, tables, and the equipment that we can find in common home. And it is also at the university, there are the furniture and equipment for lecture, such as chalkboard, tables, books, chairs, and some others.

The cinematography of this scene shows applying the camera for shooting the scene using some techniques from the camera movement, camera shot, camera framing and camera angle. From the camera movement, we find some zoom shots; zoom in and zoom out. Zoom shot gives effect to draw attention to a specific detail in the shot, give a character power, and to emphasize a comedic or dramatic moment. The first is when the camera shoots Will Hunting, the main character at the opening shoot to introduce him; when Chuckie, Will's closest friend comes to Will's house driving his car; when Chuckie come toward Will's house; and when Chuckie and Will leave Will's home by car.

The angle gives viewers a good view of what state the house is and also a good view of what the character is wearing and how he acts. The lighting in this scene, light to the left and right side of the door is dark and the sunlight is shining on the door which gives the impression that the house may be a bit messy and it does not look very nice but who is inside is a lot nicer. It is also applied in the Lambeau's classroom.

\subsubsection{Bar Scene}


One night after work, Will and his best friend Chuckie and a couple of their other friends, Billy and Morgan go to a bar near Harvard University. At the bar, Chuckie spots a beautiful woman, Skylar, and he kicks on her, claiming to be a Harvard student himself. One of Skylar's fellow co-eds, Clark, tries to humiliate Chuckie, challenging his knowledge of American colonial history. Will steps to Chuckie's defense, matching Clark step for step with historical facts he had memorized. A potential fight is eventually defused and Will finds that Skylar is attracted to him, getting her phone number. The scene is often called "them apples" scene because at the end, Will tells Clark he got one of the girls' phone number. As he is leaving the bar he asks, "How you like them apples?"

The costumes or clothing and its accessories are for hanging-out clothes, and so does the use of make up. For examples the clothing worn by Skylar, a black singlet which implies that she is fashionable girl. The props used are also for the bar prop, like bottles of beer, lamps with dim light, wine glasses, and the other equipment for bars as common.

The cinematography of the scene applies the camera for shooting this scene used some techniques from the camera movement, camera shot, camera framing and camera angle. From the camera movement, viewers find some zoom shots; zoom in and zoom out, such as when Chuckie closes to the girl, Will follows Chuckie when there is someone who bothers Chuckie. Viewers also find pan shot when Will argues with Clark; dolly shot for shoot the conversation between Will and Skylar; truck shot, when the camera shot Will and his buddies communication; and also rack focus when the camera shoots two girls coming into the bar in blur and then in clear figure, that is Skylar.

The angle gives viewers a good view of the scene to show how the character are acting. The lighting in this scene, light to the left and right side of subject gives the impression that the atmosphere is really different from the place out of bar. It shows the night life. All these elements of cinematography can be found in the Appendix E.

\subsubsection{Fight Scene}

The scene is going on when Will and his buddies go home from watching baseball match. The cinematography technnique in this scene is complex enough. Applying camera of movement and placement that viewers can see is the using of zoom shot, zoom in or zoom out when the fighting happens. How Will and his buddies hit and kick their oppsite guys are be focussed in zoom shoot. But on the other shot we also find, tilting technique when Will is arrested by the 
police, pan shot when the camera covers to shoot the fighting that is going on in some side of the base ball field, dolly shot, when covers all the guys involed in fighting, pedestral, too, in covering the guys who involved in fight, a truck technique to focuses the expression of each guy who fight from one side to others, and rack shot, too. From the technique of cinematography applied in this scene, viewers can see as if the fighting is so real, so rough and wild fighting. All these elements of cinematography can be found in the Appendix F.

\subsubsection{Courtroom and Jail Scene}

A few days later Will attacks a youth who had bullied him years before in kindergarten, and he now faces imprisonment after beating up a police officer who breaks up the fight, a tough judge refuses to be tricked by Will's sharp knowledge of law precedent, which includes citing a case from the 1700s. Realizing Will might have the potential to be a great mathematician, such as the genius Évariste Galois, Lambeau intervenes on his behalf, offering him a choice, either Will can go to jail, or he can be released into Lambeau's personal supervision, where he must study mathematics and see a psychotherapist to help him with his anger and defensive personality. Will chooses the latter even though he seems to believe that he does not need therapy.

The cinematography applied in this scene uses some techniques from the camera movement, camera shot, camera framing and camera angle. From the camera movement, viewers find some zoom shots; zoom in and zoom out, such as when Will defend himself from the prosecutor's indictment. Viewers also find pan shot when they involve in debate of the indictment trial; truck shot; and also rack focus. The angle gives viewers a good view of the scene to show adjudication is on progress. The lighting in this scene, light to the left and right side of subject gives the impression that the atmosphere is really show in the process of judiciary. All these elements of cinematography can be found in the Appendix G.

\subsubsection{Will's Theraphy and Park Scene}

The theraphy that Will has to be followed takes places at Lambeau's office, Sean's office, Sean's apartment, and in a park. After having some theraphies from some different therapists and psychologists, Will has a last theraphist named Sean McMaguire, an estranged old friend and the MIT classmate of Lambeau.

In Sean's room, several shots are used in the scene at different times. Over the shoulder and mid shots, both allow the setting to be seen, reminding the viewers of the intimacy of the 
conversation, with just the two characters in a small office. As their discussion heats up, the shots get closer, moving from mid close ups to close ups, and there is also movement with the depth of focus, when Will begins to insult Sean, the shot changes from deep to shallow focus, allowing both of the characters emotions to be seen in the same frame. The attention is purely on the characters, and it creates a less choppy sense during their conversation, with the focus shifting slowly and less noticeably than a typical cut. The technique of the camera placement is also used in the park scene.

The props around the office may help to indicate what kind of a person Sean is, with what looks like mess everywhere, and his appearance may also match that his unkempt beard and casual clothing. Similarly, Will also has quite a messy appearance, wearing a t-shirt with holes in it tucked into trousers. There is both natural and artificial lighting, with sunlight coming through a window, missing Will's face as he insults Sean's painting, but it creates a fairly harsh effect, allowing the viewers to see their tired expressions. This is particularly important after Will leaves, as Sean is left alone, looking miserable.

This furthers still when Sean goes home, as the viewers see alcohol as an immediate prop, suggesting his possible unhappiness, and unwillingness to deal with other things such as the dirty dishes by his sink. Will's feeling of repressed because of self blame and the fear of not being loved are what has held Will back his whole life, until his breakthrough in therapy, he seems to have believed he was unworthy and incapable of having a better life, including his girlfriend's love. All these elements of cinematography can be found in the Appendix H.

\subsubsection{The Closing or Ending Scene}

The ending scene is great because it has two callbacks. One is the line 'have to see about a girl' as well as Chuckie showing up to Will's empty house. There is a clear resolution because we know Will goes to see Skylar and get out of Boston, and we are left although we want to wait a little bit longer.

The scene takes place at Sean's and Will's apartment. Will goes to Sean's apartment to send Sean a notice that Will will go to see Skylar in California. Meanwhile at the similar time, Chuckie and Will's other buddies, Morgan and Billy go to Will's apartment to pick him up for having fun like usual they do. Of course, Chuckie can not find Will at his apartment. Chuckie realizes Will is not there, but he thinks Will goes to meet Skylar. Chuckie smiles meaningfully by himself for his buddy’s happiness. 
The cinematography technique in this scene is variety enough. Applying camera of movement and placement that we can see is the using of zoom shot, zoom in or zoom out when Will comes closer to Sean's apartment and Chuckie comes closer to Will's apartment. How Will and his buddies drive their car to reach their destinations. But on the other shot we also find, tilting technique to shoot Chuckie in front of Will's apartment and Will, in Sean's apartment.

The camera covers to shoot Sean's activities in packing his clothes, his things, Will who looks Sean from out of Sean apartment, and Sean just sees Will from inside his apartment, and also Chuckie who walks back and forth in front terrace of Will's apartment. The using of dolly, pedestral, truck, and rack shot techniques to apply the expression of each guy who focus to their mind. and activities they do. The song of Miss Misery composed by Elliott Smith closes this movie as it ends by Will driving his car to his new life.

\subsection{Film Sound of Good Will Hunting}

Throughout the initial scene set in Sean's office, there is only diegetic sound of the two characters talking. The lack of background noise helps the viewers to fully focus on the dialogue, with the build of tension transferring easily to viewers, coming across powerfully without the disturbance of other sound such as music. It also enables the emotion in their voices be heard clearly.

\subsubsection{Music}

Like so many awesome films from the 1990s, Good Will Hunting had its main score written by legendary composer Danny Elfman. And as with any Elfman score, the music has a real sentimental tinge to it. It makes us think of leaves falling off the trees in autumn. It does not really do a great job of showing the dark side of Will Hunting but maybe Elfman figured that anything too dark would make it hard to concentrate on what was going on in the movie or the opening scene. Viewers will also find four songs by the singer-songwriter Elliott Smith in this movie, including the song "Miss Misery" that he recorded for the closing scene. If they want to see the dark side of Will's experience, this last one is the song for them.

\subsubsection{Dialogue}

The dialogue of Good Will Hunting is sharp and brilliant. It means that the dialogue used in the movie can fulfill the movie dialogue functions such as bring conflict, character, information, emotions, and move the story forward. In particular, it causes various emotions by the viewers, 
from laughter to recognition, from empathy to upset, a complete scale of emotions. The dialogue is realistic, sometimes it is too fast by using accents thick, and otherwise it is too deep for the viewers to understand them. It means that the dialogue is a real as we use in the daily live. All dialogues or monologue flow naturally. That means that the dialogue used in this movie is natural, the dialogue spoken in a style to mimic real life conversation, including natural rhythms and phrases that give the viewers the impression the dialogue is realistic. Here are the examples of dialogues used in Good Will Hunting movie.

\subsubsection{Soundtrack}

The musical score for Good Will Hunting was composed by Danny Elfman, who had previously collaborated with Gus Van Sant on To Die For and would go on to score many of the director's other films. The film also features many songs written and recorded by singersongwriter Elliott Smith. His song "Miss Misery" was nominated for the Academy Award for Best Original Song. Elfman's score was also nominated for an Oscar. These are the soundtrack of Good Will Hunting movie released on December 2, 1997.

\begin{tabular}{|c|l|l|c|}
\hline No. & \multicolumn{1}{|c|}{ Title } & \multicolumn{1}{|c|}{ Music } & Length \\
\hline 1. & Between the Bars (Orchestral) & Elliott Smith & $1: 09$ \\
\hline 2. & As the Rain & Jeb Loy Nichols & $4: 51$ \\
\hline 3. & Angeles & Elliott Smith & $2: 55$ \\
\hline 4. & No Name \#3 & Elliott Smith & $3: 10$ \\
\hline 5. & Fisherman's Blues & The Waterboys & $4: 19$ \\
\hline 6. & Why Do I Lie? & Luscious Jackson & $3: 27$ \\
\hline 7. & Will Hunting (Main Titles) & Danny Elfman & $2: 41$ \\
\hline 8. & Between the Bars & Elliott Smith & $2: 21$ \\
\hline 9. & Say Yes & Elliott Smith & $2: 15$ \\
\hline 10. & Baker Street & Gerry Rafferty & $4: 08$ \\
\hline 11. & Somebody's Baby & Andru Donalds & $3: 10$ \\
\hline 12. & Boys Better & The Dandy Warhols & $4: 32$ \\
\hline 13. & How Can You Mend a Broken Heart? & Al Green & $6: 18$ \\
\hline 14. & Miss Misery & Elliott Smith & $3: 12$ \\
\hline 15. & Weepy Donuts & Steve Bartek, Danny Elfman & $3: 48$ \\
\hline
\end{tabular}




\section{Total length:}

\subsubsection{Composition}

The composition of Good Will Hunting movie is beautiful enough. Through the props or sets, costumes, and figure expression and movement, viewers can see the characters grew and change throughout the movie. From the beginning of the film viewers can notice a lot about Will Hunting through the sets and props in his room. There is a huge collection of books on the ground surrounding him. His bed does not include a frame, but rather just a mattress and a blanket on the ground. Accompanying the room is also no cabinets, two chairs and a lamp on a crate of milk. It shows to the viewers that Will likes to read all different types of literature and he is intelligent. As we know, people who like reading have more knowledge and they are smart.

The use of color in this movie is very natural. The use of warm ambers is a smart way to create a sense of humanity and creates a strong sense of empathy for Will. When Will is in a place he feels safe and comfort, the colors are very warm and appeasing. For example, when he is in Skylar's room at Harvard, or in Sean's office, or in his apartment, the dominant color is amber.

The applying of camera technique used in this movie is so many varieties. Long shot contains landscape but gives the viewers more specific idea of setting. A long shot may show the viewers the building where the action will be taken. Full shot contains a complete view of the characters. From this shot, viewers can take in the costumes of characters and may also help to demonstrate the relationships between characters. Close-up contains just one character's face. This enables viewers to understand the actor's emotions and also allows them to feel empathy for the character.

Bird's Eye Angle, an angle that looks directly down upon a scene often used as an establishing angle, along with an extreme long shot to establish setting. High Angle is a camera angle that looks down upon a subject. A character shot with a high angle will look vulnerable or small. These angles are often used to demonstrate to the viewers a perspective of a particular character. Low Angle is a camera angle that looks up at character. It makes character look more important and powerful. An aerial shot during the playground fight scene is to re-show the sense of unity Will's buddies have. It creates an amazing sense of emotional connections. It was 
absolutely beautiful. Overall the composition and cinematography techniques used in this movie are good.

\subsection{Defect of Good Will Hnting Movie Making}

The film relies too much on dialogue. There are some hugs, some tears, some shouting, but to know more about souls of Will and Sean, we have to listen to speech after speech they talk. A less interesting of covering film gives the impression of monotone sense, and there is less backsound hitch that it can live the atmosphere more, and it is not noticed. We can say this film with drama genre is a bit boring because it is lack of musical effects. The storyline sometimes jumps from one storyline to another even though it happens at the same time and it sometimes makes viewers may think that that happens in diferrent times. The film ending or closing is still hanging because it is uncertain whether Will Hunting will successfully find and meet Skylar or not. But the viewers can assume that Will Hunting will meet and live together with Skylar who really loves him.

The story of Good Will Hunting movie takes from a bad boy, so the use of rough dialogue may be it is one of the defect of the film. And because of it, the movie can not be watched by people from any all ages, it is not suggested for children who are still minors. Overall, this movie is interesting enough and the mise-en-scene is, too. All details in a motion picture are important but the mise-en-scene will always be the most important aspect of every film. There are some things we can learn for this life from this movie like there is nothing perfect in this world, even love, as people grow older, they will understand about love, pain, feeling of loss, and the life itself.

\section{Conclusion}

The elements of mise-en-scéne in Good Will Hunting Movie is so complex. People can find almost all the elements of mise-en-scéne from human figure such as acting, acting style, performance, figure placement (blocking), costumes, props and make-up, cinematography, lighting, and composition. Mise-en-scéne of Good Will Hunting movie is so interesting as viewers can see from the beginning of the film, they can notice a lot about Will Hunting who Matt Damon plays, through the sets and props in his room. The costumes and make-up are not overdone, all are done as a real life. The cinematography techniques used in this movie are so 
beautiful. Viewers can find applying camera movement and placement used in this movie in many techniques, from camera shot, camera frame, camera angles and lighting techniques in every scene or framed they can catch.

The aspect of mise-en-scéne plays an extremely active role in movie and it also applies to Good Will Hunting. Mise-en-scéne of Good Will Hunting sets the mood of each scene, describes who each character is and what their objective is in the film. Mise-en-scène that is built in Good Will Hunting movie reinforces the idea of the movie supporting by all elements that work properly as long as the movie is showed. Mise-en-scène in Good Will Hunting movie can evoke emotions viewers that permeate the whole movie.

Mise-en-scène can be felt like a convoluted and overly-complicated concept to understand, but it is necessary to look at what a camera is capturing from a wider perspective. It is a concept that helps people look at the shot as a whole, not just with the cinematographic elements (lighting, camera angle, etc.), character elements (blocking, wardrobe, etc.), or set design (props, decor, etc.) alone. Mise-en-scène is not about the individual elements, it is about how they harmonize to create the mood and story.

\section{References}

A.S. Hornby. (1995). Oxford Advanced Learner's Dictionary of Current English $5^{\text {th }}$ ed). Oxford: London University Press.

Bordwell, David, and Thompson, Kristin. (2003). Film Art, An Introduction ( ( $^{\text {th }}$ ed). New York: The Mc Graw-Hill Companies.

Brown, Blain. (2012). Cinematography Theory and Practice Image Making for Cinematographers and Directors $\left(2^{\text {nd }}\right.$ ed). United States of America: Focal Press.

Monahan, Dave, and Barsam, Meran, Richard. (2009). Looking at Movies An Introduction to Film $\left(5^{\text {rd }}\right.$ ed). United States of America: W. W. Norton \& Company, Inc.

Monahan, Dave, and Barsam, Richard, and Gocsik, M. Karen. (2010). Writing about Movies (4th ed). United States of America: W.W. Norton \& Company, Inc.

Sreekumar, Jayakrishnan, and Vishwa, Amrita. Vidyapeetham. (2015) Creating Meaning through Interpretations: A Mise-En-Scene Analysis of the Film 'The Song of Sparrows' Online Journal of Communication and Media Technologies

https://www.ojcmt.net/article/creating-meaning-through-interpretations-a-mise-en-sceneanalysis-of-the-film-the-song-of-sparrows-5687 
Sumarno, Marselli. (1996). Dasar-Dasar Apresiasi Film (1 ${ }^{\text {st }}$ ed). Jakarta : PT. Grasindo.

Toblas, W, Ronald. (1993). 20 Master Plots (and How to Build Them) ( $1^{\text {st }}$ ed). United State of America: Writer's Digest Books, an imprint of F\&W Publications, Inc.

Thompson, Roy, and Bowen, J, Christopher. (2013). Grammar of the Shot (2 ${ }^{\text {nd }}$ ed). United Kingdom: Focal Press Taylor and Francis Group.

Vanderstoep, W, Scott, and Johnston, D, Deirdre. (2009). Research Methods for Every Life Blending Qualitative and Quantitavive Approaches ( $\left.1^{\text {st }} \mathrm{ed}\right)$. United State of America : Jossey-Bass A Wiley Imprint 